\title{
Da diferença perigosa ao perigo da igualdade Reflexões em torno do paradoxo moderno
}

\section{Ruth M. Chittó Gauer*}

Mary Douglas é uma destas autoras que quando nos deparamos na estante de livros, ficamos tentados em relê-la. Há alguns dias, isso ocorreu. Deparei-me com Pureza e perigo (Douglas, 1976. p. 56), livro que trabalhei na década de 70. Relendo algumas passagens do livro, que destaquei há tanto tempo, verifiquei o enfoque dado pela autora sobre as questões da pureza, do perigo, da impureza, da sujeira. A ênfase no exame destas questões está vinculado a outra problemática, não menos importante, que a autora trabalha, qual seja: a questão da ordem. Pensei como a ordem fundamenta todo um padrão de comportamento que nem sempre costumamos relacionar à impureza e ao perigo. No entanto, nada mais apropriado que pensar na ordem para compreender a desordem assim como todo o tipo de discriminação. A sujeira é um fato que nos repugna, temos horror a certos tipos de sujeira, passamos pensando o quanto é importante a limpeza, a pureza e a ausência de qualquer perigo. Tudo o que nos cerca deve estar imune à contaminação e à impureza, mesmo as mais microscópicas. A ordem está colada à organização: todas as coisas em seus lugares e todos os lugares com suas coisas igualmente ordenadas e purificadas.

* Historiadora, antropóloga, doutora pela Universidade de Coimbra, professora dos programas de pós-graduação em História e em Ciências Criminais na Pucrs. Pesquisa financiada pelo CNPq. Email: chitto@pucrs.br 
A obsessão pela limpeza é configurada pela disciplina. Nada mais importante para essa obsessão que a busca desesperada pelo modelo que retrate limpeza, normalmente associada ao belo. A beleza está vinculada à aparência de limpeza do corpo, o qual deve estar livre de impurezas, isto é, com ausência de resíduo, mesmo os mais microscópicos, como se isso fosse possível. A estética, nomeadamente no século XIX, colou a limpeza de tal forma que se tornou uma obsessão. Desde a era vitoriana podemos observar esse comportamento obsessivo principalmente através das tarefas femininas. Embora as casas e mesmo as ruas das cidades exalassem odores não muito agradáveis, as mulheres tinham uma jornada diária de trabalho que hoje não podemos sequer imaginar, ligada às tarefas da casa. $\mathrm{O}$ tempo de limpar, lavar, passar, desinfestar etc. ocupava mais de doze horas diárias de trabalho pesado e estafante. Esse fato não iniciou no século XIX. Muito antes as questões de pureza, higiene e sujeira estabeleciam a ordem da casa (espaço privado) assim como a ordem do espaço público.

A limpeza dos espaços públicos foi e é também realizada pelas instituições vinculadas à esfera da administração e das políticas públicas (a casa, exemplo de espaço privado, também foi submetida à disciplina da higiene).

Desde a antigüidade o isolamento foi uma prática utilizada para evitar a contaminação, o exemplo histórico de exclusão mais conhecido é o dos leprosos. Na modernidade essa prática continuou, passou-se a isolar casas, hospitais, até quarteirões inteiros de cidades como forma de proteção dos espaços não contaminados. Esses locais vistos como perigosos deveriam estar bloqueados como forma de imunidade dos locais limpos. $\mathrm{O}$ isolamento como medida de exceção constituía-se na única forma de proteção.

A reflexão sobre a sujeira envolve pensar relação entre a ordem e a desordem. Nada mais eficaz do que a disciplina moderna para garantir a ordem. As técnicas disciplinares preocupam-se não apenas com a sujeira e a doença, elas trataram e tratam de organizar meios para disciplinar todas as formas de expressão e de comportamento, da forma como sentamos à mesa até a mais cotidiana comunicação buscando os ideais de ordem. A civilização perseguiu freneticamente o controle e o domínio de toda e qualquer forma de perigo. $\mathrm{O}$ respeito com as conversões e a higiene se constitui em duas ferramentas eficazes de controle social. A representação sobre a limpeza e a pureza pretende eliminar a entrada do grotesco, do monstruoso, do feio, do disforme, do 
violento, em resumo, de todos os modelos perigosos para as convenções estabelecidas pela civilização. Talvez possamos afirmar que o modelo de igualdade, tal como foi criado nos tempos modernos, tenha estruturado todas as ações sociais e políticas desde seu início com o objetivo de eliminar diferenças contaminadoras e, portanto, perigosas.

A modernidade disciplinou não apenas os homens, mas todas as coisas que pudessem estar fora do lugar. Mary Douglas (1976, p. 18) refere que o reconhecimento de qualquer coisa fora do lugar constitui-se em ameaça, e assim as consideramos desagradáveis e as varremos vigorosamente, pois são perigos em potência. Neste processo de limpeza os perigos são semiidentitários. A modernidade criou essa compulsão, esse desejo irresistível de ordem e de segurança. O mundo perfeito, utopia dos iluministas, seria totalmente limpo e idêntico a si mesmo, transparente e livre de contaminações. A racionalidade expressa pelas convenções e pelas leis tinham como fim imunizar a sociedade contra a violência, a corrupção, a sedução das crenças e demais impurezas. Os modernos esqueceram, no entanto que não haveria imunidade para o egoísmo, o niilismo e para a exploração de um número enorme de seres humanos.

Quais os procedimentos políticos, jurídicos, administrativos, e quais os dispositivos que permitiriam a busca da construção e manutenção de uma sociedade higienizada e imunizada? A compulsão pela ordem esteve, e está, presente nas sociedades ocidentais, seja nos regimes políticos das democracias liberais seja nos regimes totalitários. Porém há que se salientar que a violência depuradora sempre esteve mais presente nos ambientes onde a exceção constitui-se a regra. A eliminação dos adversários políticos é vista como uma forma de limpeza. Ela visa a atingir os opositores e a todos os que podem se constituir em perigo. Os exemplos históricos mais recentes como o nazismo, fascismo, comunismo, assim como as formas mais diferenciadas de ditaduras na contemporaneidade comprovam, sem muito esforço, a utilização de práticas de saneamento dos sistemas políticos. Nos estados de exceção, os perigosos, todos os que são identificados como potencialmente contaminadores, devem ser purificados ou eliminados. Quando os estados passaram a estabelecer políticas públicas para cuidar do corpo da população, purificando a sociedade e assim "protegendo" e ordenando a vida pública e privada, abriu-se a possibilidade para a inclusão de alguns e logicamente a exclusão de outros. 
A manutenção do modelo igualitário ganha espaço na mesma proporção que os regimes totalitários e de exceção se aprofundam. Quanto maior a exceção, maior a igualdade, por mais paradoxal que possa parecer. Dumont (1985, p. 270-274) sugere que o nacional-socialismo tenha revelado a essência - mesmo que essa opinião possa causar algum, mas não suficiente, incômodo mal estar - da sociedade contemporânea. A atomização do indivíduo fez com que prevalecesse uma tensão contraditória. Por um lado, a emancipação gerou o individualismo arrebatado, por outro, uma coletivização ao extremo, isto é, o nivelamento de todas as diferenças, conduziu à pior das tiranias. Esse fato eliminou o caráter carismático do vínculo social e abriu a possibilidade de eliminar os laços de solidariedade que uniam as comunidades e estruturavam a sociedade. A ausência de laços de solidariedade implica na abertura da exclusão em nome da ordem igualitária totalizadora. Os perigos precisam ser eliminados, limpos, depurados, para que a totalidade se faça no conjunto da sociedade. Contemporaneamente a sociedade de massa revela a impossibilidade de pensar na forma, na essência e no modelo. Esse aspecto traz problemas para a democracia.

Partindo da premissa que a democracia tem por base uma igualdade, estruturada na naturalização do indivíduo, constituída pelo direito, o que pressupõe a exclusão do desigual (diferente) em nome da ordem, cabe aqui lembrar que nesse caso a força política se sustenta na medida em que se purifica colocando distância entre a ordem e a desordem, entre a pureza e o perigo, com a tentativa de eliminação do estranho, do desigual, impedindo que ele se torne um perigo ameaçador da homogeneidade. Se representação e identidade constituem, nas palavras de Franco de Sá (2004, p. 34, 51-52), a força de uma democracia, não e possível falar de democracia que prescinda da identidade. É Jaques Derridá quem tenta pensar "a democracia por vir" através do apelo de uma outra fraternidade. Para ele, a desnaturalização estava em obra na própria formação da fraternidade. A presença de qualquer grau de homogeneização e de exclusão daquele que não é homogêneo implica na configuração de uma totalidade. Na contemporaneidade a soberania do estado passou a ser a soberania do direito. Hans Kelsen (1979) defendeu a identidade entre o Estado e a própria ordem legal. A teoria pura do direito é vista pelo autor como forma acabada da universalidade da ordem jurídica em termos de racionalidade. A partir desta constatação, o exercício da soberania, nos regimes democráticos, apresenta-se como a soberania da ausência de soberania. Para 
o autor, a teoria pura do direito está para a soberania como a verdade está para a evidência. Seguindo essa reflexão, podemos encontrar nas teses de Schmitt (apud Sá, 2004), a questão da exceção. O autor explora profundamente a relação entre o ocaso da soberania política e a emergência do conceito de guerra humanitária enquanto guerra discriminante ou criminalizante, isto é, guerra total, exemplo de regime de exceção. A própria soberania, na atualidade, sofre evidências devastadoras. A busca de novos fundamentos não será suficiente para imunizá-la da correção que é uma forma de evidência devoradora. A soberania da igualdade, que nasceu naturalizada, ficou profundamente contaminada pelos vários eventos do século XX entre os agentes contaminadores mais emblemáticos citamos os regimes de exceção - o nazismo e os fascismos.

Fica evidente que a política da igualdade potencializa a violência de várias formas: eliminando todo e qualquer outro, o diferente, o sujo, o impuro, o anormal, o doente, enfim tudo o que causa estranheza, perigo, que lembra sujeira e desordem. O tecido social precisou ser impermeabilizado a tal ponto que a sua proteção torna difícil pensar em rupturas que permitam a contaminação. As práticas políticas adotadas na modernidade, em nome da igualdade, que visava à eliminação das hierarquias medievais, estavam pautadas na prescrição de condições de controle dos comportamentos individuais e coletivos. Essa pretensão de controle social nada mais é que a submissão da ação pelo comportamento: a ação enquanto possibilidade de criação e o comportamento pautado pela previsibilidade. A perspectiva da previsibilidade encontra-se vinculada à lógica binária e dual típica do pensamento moderno. Reafirma o paradigma do "ou isto ou aquilo", do sujo e do limpo, do modelo e do antimodelo. No entanto, o pensamento moderno estruturou uma forma de exclusão que obscureceu a possibilidade de preferência. Poderíamos preferir a inclusão e não a exclusão, ou seja: isto, aquilo, além de outros.

A lógica da exclusão foi a base para a construção de termos como "classe", "raça", "gênero", entre outros, que serviam à identificação dos sujeitos. Hoje esses termos dissolvem-se. As dimensões de territorialidade que circunscreviam os espaços sociais romperam-se e a ordem das coisas, tal como pensada na modernidade, embasada na premissa da inclusão e da exclusão, deixou de ser a norma. Por intermédio de alguns fenômenos contemporâneos, dá-se um processo de "despurificação" das identidades so- 
ciais. A retenção de uma essência identitária - esforço nostálgico de afirmação - é cada vez menos viável. Podemos observar que todas as práticas culturais estão sob o contato contínuo entre o local e o global, fato esse que impede a simples questão que pautou a inclusão-exclusão ao mesmo tempo em que impossibilita pensar uma igualdade tal como defendida pelos direitos humanos. Alguns exemplos mais marcantes podem ser apontados: o caso da mulher paquistanesa condenada à morte por crime de honra o qual foi cometido por seu irmão; as famílias dos homens bomba que são punidas pelo crime cometido por eles quando suas casas são destruídas; noventa e cinco por cento dos casos julgados no Paquistão são realizados pelos conselheiros locais que julgam segundo os princípios específicos de sua cultura, desconhecendo a questão dos direitos humanos. Esses fatos suscitam questões que focalizam aqueles processos que são produzidos na articulação de diferenças culturais. Há uma intensa negociação nesses "entre-lugares", lugares de negociação em andamento, locus do "aqui e agora". A soma das partes envolvidas e suas demandas não implicam num único resultado, mas implementam múltiplas negociações e sobredeterminações (como o dispositivo irrefreável tal como analisado por Foucault).

O "embate cultural" - que caracteriza as crises sociais da atualidade não envolve, necessariamente, o duelo entre tradição e modernidade. O advento dos fundamentalismos (tentativa lograda de resgate) é apenas um lado do caleidoscópio social onde as questões da ordem, do perigo, da inclusão e, sobretudo, da exclusão constituem-se no lócus das políticas atuais.

As reflexões sobre os temas acima abordados são fundamentais para a compreensão da crise epistemológica que vivemos. A premente necessidade de relativizar a verdade e vincular a análise a um pensamento heterotópico, não consensual, permitiria uma maior visibilidade da crise em que estamos todos envolvidos. Esses temas não se encontram necessariamente juntos. Eles podem aparecer no desespero epistemológico, no relativismo, entre outros lugares. O certo é que a sociedade já não consegue ser explicada pelo positivismo e pelo determinismo racionalista. Não há preparação para lidar com o erro, com as impurezas, só podemos pensar nelas como possibilidade de nos imunizarmos. O Caos dá visibilidade a uma instabilidade que é apenas aparente. Qual o lugar para uma realidade única? Em tempos polifônicos é impossível pensar na Babel. 
Vivemos uma época onde a própria temporalidade deixou de ser vista de forma totalitária. A superação do eterno retorno, tempo cíclico, foi substituído pelo tempo linear projetivo que estruturou a visão de que o tempo se transformou em história. A base dessa visão estruturada na totalidade linear e no determinismo racionalista foi fragmentada. Essa visão foi quebrada pela simultaneidade. O presente se torna imprescindível. Ao lado da simultaneidade temos a invisibilidade, os desvios sociais, ausência do estado nos bolsões de miséria gerando a violência. Qual o papel do estado frente à invisibilidade? Frente à pergunta, a sedução poderia ser dispensada? No entanto, identificar o discurso em nível de senso comum torna-se fundamental para visualizar como o discurso da purificação está presente inconscientemente. Somos seduzidos por outros mecanismos que dão maior visibilidade uma vez que as palavras não possuem a transparência necessária.

A impossibilidade de uma verdade única, de uma identificação totalizante, associada a uma velocidade, que segundo Virilio (1973) é a velhice do mundo, matam o discurso político. Nesse quadro, o consensual fica sendo os totalitarismos, os fundamentalismos, enfim, todos os determinismos totalitários próprio de tempos de descrença e de desconstrução de verdades limpas, ordenadas, protegidas dos perigos, enquadradas na limpeza purificadora que ordena o social com a possibilidade de termos a ditadura do modelo revelador da ordem dos Estados Nacionais, tais como pensados desde o século XVIII. Outra pergunta se faz necessário: o consensual ficaria sendo o totalitarismo? Todos os determinismos são totalitários? Propor um pensamento heterotópico, não consensual, estruturante, sem levar em conta que as teorias do consenso existem para tornar invisíveis as manifestações políticas partidárias. Onde estão os requisitos dos totalitarismos? Em todos os níveis sociais as suas manifestações ocorrem quotidianamente.

A questão não envolve a justaposição da diferença, ao lado do consenso cultural, não se trata apenas de inclusão e reconhecimento das "minorias", nesse caso, o ideal essencializador (ou identitário) seria reforçado. Concordo, neste sentido, com Bhabha (2001, p. 20-46) sobre a possibilidade de afirmar o deslocamento do lugar onde as relações sociais se concretizam. O autor refere que os "entre-lugares", as fímbrias, os interstícios, enfim, correspondem ao lócus no qual se exercitam as relações sociais. As diferenças culturais são exercitadas engendrando novos espaços e temporalidades, o que implica um deslocamento constante, anulando as categorias de "centro" e "periferia". 
Para Bhabha (2001), "essa passagem intersticial entre identificações fixas abre possibilidade de um hibridismo cultural que acolhe a diferença sem hierarquia suposta ou imposta". O presente "é o tempo de agora", capaz de se autogerar, distante do historicismo teleológico das "causas". Nem ruptura, nem projeção, abandona-se a seqüencialidade.

O autor refere ainda que o presente torna-se "obeso", alargado, expandido pelas experiências nascidas do hibridismo cultural. O presente "não tem lugar" ele é ex-cêntrico, isto é o fim da hierarquia centro-periferia e sua correspondente temporalidade (o presente não é o meio do caminho entre passado e futuro, mas, paradoxalmente, contém ambos (porque os re-significa) e nenhum, ao mesmo tempo (na medida em que, nessa re-significação, subverte a fixidez de suas características).

A idéia da homogeneidade vista como pureza das culturas nacionais, ou mesmo das raças, a exemplo do nazismo, fica comprometida, passando a ser questionada. É o ocaso do etnocentrismo. A interferência das minorias ocupa o território da cultura, mas não produz a multiplicação da prosa austera dos refugiados políticos e econômicos. É nesse sentido que a fronteira se torna o lugar a partir do qual algo começa a se fazer presente em um movimento não dissimilar ao da articulação ambulante, ambivalente, do além. Como decorrência, o exotismo minoritário não é um mix de diversidades mas uma transformação qualitativa: o nascimento de novas conexões que extrapolam as dualidades: minoria $\mathrm{X}$ maioria, capital $\mathrm{x}$ trabalho, estado $\mathrm{x}$ sociedade, metrópole x colônia, pureza x perigo e assim por diante. $\mathrm{O}$ que é impressionante no novo internacionalismo é que o movimento do específico ao geral, do material ao metafórico, não é uma passagem suave de transição e transcendência (Bhabha, 2001, p. 25-26). A meia passagem da cultura contemporânea como no caso da própria escravidão, é um processo de deslocamento e disjunção que não totaliza a experiência.

Ao lado dessa reflexão, de releitura da contemporaneidade, há também, um movimento político. Na visão do autor, "na medida em que esse espaço do além torna-se um espaço de intervenção no aqui e no agora". Trata-se de um movimento de "renovação" do passado, reconfigurando-o como "entrelugar" contingente, que inova e irrompe a atuação do presente. Segundo Bhabha, na linguagem bejaminiana, é quando o presente explode para fora do contínuo da história. Ao invés do continuum cristalizado, no sucessivo 
de passado-presente, o diálogo cultural engendra uma espécie de "novo conceito de novo", caracterizado pela emergência constante da "tradução cultural". Isto é, a modernidade tropical pós-colonial não é a Mesma do "Velho Mundo" - autenticada - tão pouco é completamente diferente desta. Igualdade na Diferença. O desejo de reconhecimento (como o "Eu não pareço com você”, da música do Rappa) introduz a negação, ao contingente, pois impõe uma transcendência (reconhecimento além do tempo). A minoria não quer ser "incluída", higienizada, tornada semelhante, mas ser reconhecida. Ainda segundo o autor (Bhabha, 2001, p. 29-59) reconhecer implica deslocar o fundo fixo da identidade, superando a diacronia da história. A tradição ocidental, que se buscou sempre a exegese da diferença, embora nunca conseguido superar o arco hermenêutico para além do outro (como o próprio em si), dá seus últimos passos. O Outro perde o poder de significar, de negar, de iniciar seu desejo histórico, de estabelecer seu próprio discurso institucional, do puro e do impuro. A experiência social da "teoria crítica ocidental" perfaz um caminho que vai da consideração do "bom selvagem" de Rousseau, ao "bom" e dócil corpo da diferença, nos discursos contemporâneos do multiculturalismo. Essa concepção permite a compreensão de experiências como sendo, ela mesma, a marca da impossibilidade de se localizar tanto uma origem, quanto uma pureza cultural. Produz um problema irresolvível de diferença cultural para a própria interpelação da autoridade cultural colonial. Como exemplo, Bhabha lembra que na relação entre hinduísmo e cristianismo, sob a égide do discurso colonialista, e para sua própria "eficácia", foi preciso encontrar catequistas nativos, que traziam consigo suas próprias ambivalências e contradições culturais e políticas. As noções liberais de multiculturalismo, de intercâmbio de culturas e de cultura da humanidade, são uma retórica que considera as culturas como portadoras de conteúdos totalizáveis, de memórias míticas e de identidade coletiva única, o arcabouço da tradição.

A luta se dá freqüentemente entre o tempo e as narrativas historicistas, teleológicas ou míticas, do tradicionalismo - de direita ou de esquerda - e o campo deslizante, estrategicamente deslocado, da articulação de uma política de negociação. Para Bhabha (2001, p. 65-68), “o tempo de libertação é (...) um tempo de incerteza cultural, e, mais crucialmente, de indecidibilidade significatória ou representacional". 
Uma cultura não pode ser auto-suficiente por causa da differance da escrita, quer dizer no processo de manifestação simbólica da linguagem porque existe, de acordo com o autor, uma diferença manifesta no próprio lugar do enunciado. Isso justifica-se porque "o pacto da interpretação nunca é simplesmente um ato de comunicação entre o Eu e o Você designados no enunciado. A produção de sentido requer que esses dois lugares sejam mobilizados na passagem para um Terceiro Espaço, que representa tanto as condições gerais da linguagem quanto a implicação específica do enunciado em uma estratégia performativa e institucional da qual ela não pode, em si, ter consciência. O que essa relação inconsciente introduz é uma ambivalência no ato da interpretação. ${ }^{1}$

O que o autor pretende é desafiar "a noção de identidade histórica da cultura como força homogeneizante, unificadora, totalizante, autenticada pelo passado originário mantido vivo na tradição nacional de um Povo". Sua perspectiva desloca a narrativa da nação ocidental de modo a tornar manifesto que o discurso sobre a "pureza" inerente às culturas (ou a pureza racial) é insustentável, mesmo antes de recorrermos a instâncias históricas empíricas que demonstram seu hibridismo. Para esse fim deveríamos lembrar que é o "inter" - fio cortante da tradução e da negociação, o entrelugar - que carrega o fardo do significado da cultura. E, ao explorar esse Terceiro Espaço, temos a possibilidade de evitar a política da polaridade e emergir como os outros de nós mesmos. Esse fim nos levaria ao abandono da inclusão-exclusão.

Importante lembrar ainda outra expressão do autor influenciada pelo pensamento de Walter Benjamim, quando cita a seguinte passagem do texto bejaminiano: "o estado de emergência em que vivemos não é a exceção, mas a regra. Temos de nos ater a um conceito de história que corresponda a

\footnotetext{
1 Para uma análise sobre a complexidade do processo de enunciação, bem como da relação entre emissor, mensagem e receptor, e suas interconexões com a teoria hermenêutica, sugerese o capítulo "Hermenêutica e Ciências Humanas" onde Luiz Eduardo Soares afirma que a linguagem "antecede o sujeito, instaura com este uma dialética, na qual representa o universal aquilo que, oferecendo-se ao sujeito, o precede e sucede, o inclui - tornando-o possível - e o exclui, prescindindo de sua intervenção para configurar-se em sua essencialidade universal, mas que, simultânea e paradoxalmente, depende dele para existir, assumindo concretude nas particularizações que ele realiza" (Soares, 1994, p. 45).
} 
essa visão" (Benjamim, 1987). A luta contra a discriminação, a opressão, o perigo da Impureza racial, entendido como sujeira, não apenas muda a direção da história ocidental, mas também contesta sua idéia historicista de tempo como um todo progressivo e ordenado. A análise da despersonalização não somente aliena a idéia iluminista de homem, mas também contesta a transparência da realidade social como imagem pré-dada do conhecimento humano. Afinal, a própria natureza da humanidade se aliena na condição da discriminação e a partir daquela "declividade nua" ela emerge, não como uma afirmação da vontade nem como evocação da liberdade, mas como uma indagação enigmática: de o que quer o homem? (cf. Fanon, 1983) desloca e questiona: o que deseja o homem negro?

Ao articular o problema da alienação cultural colonial na linguagem psicanalítica da demanda e do desejo, Fanon questiona radicalmente a formação tanto da autoridade individual como da social na forma como vêm a se desenvolver nos discursos da soberania social. Para ele, "tal mito do Homem e da Sociedade é fundamentalmente minado na situação colonial. A vida cotidiana exibe uma 'constelação de delírio' que medeia as relações sociais normais de seus sujeitos: o preto escravizado por sua inferioridade, o branco escravizado por sua superioridade, ambos se comportam de acordo com uma orientação neurótica". A esse quadro social, o autor chama de "delírio maniqueísta".

De acordo com Fanon, "o que é freqüentemente chamado de alma negra é um artefato do homem branco". Bhabha afirma que esta transferência revela a incerteza psíquica da relação colonial porque suas representações fendidas "são o palco da divisão entre corpo e alma que encena o artifício da identidade", uma divisão que atravessa tanto a pele branca quanto a preta no processo de firmamento da autoridade individual e social. Daí emergem três condições subjacentes a uma compreensão do processo de identificação na analítica do desejo:

a) "existência" não é transcendente, mas dá-se em relação a uma alteridade, seu olhar e seu locus. Ou seja, o colonizador, só existe em relação ao colonizado e o negro em relação ao branco. Esse pensamento supera o arco hermenêutico; 
b) o próprio lugar da identificação já contém uma cisão porque "é precisamente naquele uso ambivalente de 'diferente' - ser diferente daqueles que são diferentes faz de você o mesmo - que o Inconsciente fala da forma da alteridade, a sombra amarrada do adiamento e do deslocamento. Não é o Eu colonialista nem o Outro colonizado, mas a perturbadora distância entre os dois que constitui a figura da alteridade colonial";

c) a identificação nunca é a afirmação de uma identidade pré-dada, nunca uma profecia auto cumpridora - é sempre a produção de uma imagem de identidade e a transformação do sujeito ao assumir aquela imagem. A demanda da identificação - isto é, ser para um Outro - implica a representação do sujeito na ordem diferenciadora da alteridade" (Bhabha, 2001, p. 76-78).

Os retratos pós-coloniais manifestam o ponto de fuga de duas tradições familiares do discurso da identidade: a tradição filosófica da identidade como processo de auto-reflexão no espelho da natureza humana - tal como o cogito ergo sum cartesiano (Descartes, 1973) - e a visão antropológica da diferença da identidade humana enquanto localizada na divisão natureza/cultura - tal como aponta Claude Lèvi-Strauss (1975) acerca do tabu do incesto. Funciona como dobradiça, da passagem, entre natureza e cultura. É a impossibilidade de reivindicar uma origem para o Eu (ou o Outro) dentro de uma tradição de representação que concebe a identidade como a satisfação de um objeto de visão totalizante, plenitudinário. Ao romper a estabilidade do ego, expressa na equivalência entre imagem e identidade, a arte secreta da invisibilidade muda os próprios termos de nossa percepção da pessoa. A própria questão da identificação só emerge no intervalo entre a recusa e a designação. Ela é encenada na luta agônica entre a demanda epistemológica, visual, por um conhecimento do Outro e sua representação no ato da articulação e da enunciação.

O poder total construído com base na impessoalidade e na igualdade permitiu o discurso da identidade que pode ser pensada como a autointerpretação política do mundo contemporâneo. A totalidade dos estados nacionais foram construídas, em boa parte, pelo sentido declinante de comunidade, a inclusão dos iguais e a exclusão dos diferentes. Por outro lado, a perda de valores espirituais unificados, que foram substituídos pela possibilidade de "liberdade" de credo, o crescimento do poder do Estado e da cultura de massas, e mesmo o aumento do conhecimento constituíram-se 
em ações políticas baseadas na liberdade mas que não desempenharam um papel social que tivesse impedido a discriminação. O historiador Jacob Burckhardt via claramente o lado decadente da natureza humana, nesse contexto, acreditava que era uma barreira permanente ao progresso. Seu argumento principal era considerar a decadência essencialmente como um decréscimo geral na vitalidade, que se originava numa certa espécie de virtude, "a moral das velhas senhoras" do cristianismo e da burguesia, que salientava a piedade, o amor ao próximo, a solicitude e falta de confiança em si mesmo.

Durkheim (1974) observou que as sociedades tiveram sempre mitos coletivos para poderem existir, e isto era precisamente o que os europeus do final do século XIX já não possuíam, ou estavam em processo de perder. Ele compreendia a suprema importância para a sociedade das crenças comuns e dos vínculos que tradicionalmente se encarnavam na religião, na família e nas lealdades sociais e vocacionais. Para ele a Europa sofria de uma anomie (colapso geral da consciência coletiva), que era o resultado da divisão do trabalho, que estimulava a mobilidade e a especialização, e deste modo não só separava as pessoas umas das outras, como as tornava críticas em relação às normas tradicionais. Para muitos, essa era a melhor explicação da decadência contemporânea. Era a crise espiritual, ou declínio das velhas crenças que deixara um vazio religioso e metafísico.

Ao voltar ao pensamento de Durkheim, Baumer (1990) coloca que é retirar-se de um novo mundo irracional do Fin-de-Siècle, para o mundo sóbrio da razão e da ciência. Durkheim só pertencia a este novo mundo irracional, no sentido em que via a decadência e procurava maneiras de a curar. Para compensar a anomie, que era a causa da doença social, era necessário planejar uma nova solidariedade moral. Para isso o autor defendeu uma nova ética secular e um novo tipo de instituição. A ética para ser ensinada nas escolas devia "salientar o dualismo da natureza humana: por um lado a individualidade do homem e a dignidade da pessoa humana, por outro lado, o lado social de sua natureza e até que ponto a sociedade o afeta, mesmo na maneira como pensa e, conseqüentemente, o que lhe deve".

Estas receitas para a recuperação, baseadas numa crença na liberdade da história tal como da natureza, ajudam a explicar a evaporação parcial do 
ânimo pessimista, durante o período Eduardiano. Contudo, o progresso fora agora desmascarado e era evidente para um número cada vez maior de pessoas que não havia nada de automático ou certo nele. Na complexidade do mundo atual há muita coisa fora do lugar - que não cabe na lógica cartesiana - daí a importância de Mary Douglas quando lembra que o reconhecimento de qualquer coisa fora do lugar constitui-se em ameaça, e assim consideramos desagradáveis e os varremos vigorosamente, pois são perigos em potência. Esses perigos, no entanto, se transformaram em condição de análise. A imposição de um modelo rígido de pureza, tal como o da igualdade moderna, se torna totalizante, conduz à exceção já que a pureza é inimiga da mudança, da ambigüidade e da diferença. Se a ânsia pelo rigor existe em todos nós temos que ter presente que o rigor está repleto de inadequação.

O tema da desilusão frente à história da violência contemporânea parece estar presente e revela a crise dos tempos atuais. Estas constatações, baseadas na crença da liberdade da história tal como da natureza, ajudam a explicar parcialmente o ânimo pessimista do período. Contudo, o progresso foi desmascarado e torna-se evidente para um número cada vez maior de intelectuais que não há nada de automático ou certo nele. As metamorfoses ocorridas no século passado afetaram as atitudes humanas em relação às tradições do passado, aos modos de expressão e o surgimento de uma nova perspectiva do mundo. Com relação ao advento de uma cultura unificadora devemos esperar o surgimento de um outro padrão cultural que possa ser gestado em um ambiente que leve em consideração os limites e as desilusões com a lógica moderna e o próprio humanismo. O vazio das convicções humanistas, os paradoxos da filosofia liberal, entre a dignidade e igualdade humanas no plano do ideal/real, as pretensões morais totalitárias que encobrem a real vontade de domínio, o desmascaramento da fácil crença no progresso, a moralidade, ela própria uma forma de imoralidade, os ataques frontais aos valores e pressupostos que fundamentavam a cultura ocidental, desmontaram a fragilidade da visão de totalidade e superioridade. Se, na frase de Dewey, a mente individual possui como função a vida social, a ciência deixou o homem procurando, às apalpadelas, uma esquiva realidade; Freud deixou-o procurando em vão uma realidade em seu próprio e mais íntimo eu; a historia explicitou esses fatos evidenciando a violência produzida pela cultura humanista iluminista. 


\section{Referências}

BAUMER, Franklin, L. O pensamento europeu moderno. Lisboa: Edições 70, 1990, v. 1 e 2 .

BENJAMIN, Walter. Sobre o conceito de história. In: Magia e técnica, arte e politi$c a$ : ensaios de literatura e história da cultura. São Paulo: Editora Brasiliense, 1987.

BHABHA, Homi K. O local da cultura. Belo Horizonte: Ed. Ufmg, 2001.

DESCARTES, René. Os pensadores. XV. São Paulo: Abril Cultural, 1973.

DOUGLAS, Mary. Pureza e perigo. São Paulo: Perspectiva, 1976.

DUMONT, Louis. $O$ individualismo: uma perspectiva antropológica da ideologia moderna. Rio de Janeiro: Rocco, 1985.

DURKHEIM, E. Reglas del método sociológico. Madrid: Morata, 1974

FANON, Frantz. Pele negra, máscaras brancas. Rio de Janeiro: Fator, 1983.

KELSEN, Hans. Teoria pura do Direito. Tradução de João Baptista Machado. 4. ed. Coimbra: Armênio Amado, 1979.

LÉVI-STRAUSS, Claude. Antropologia estrutural I. 1975.

—. O pensamento selvagem. Campinas: Papirus, 1989.

SÁ, Alexandre Franco de. Metamorfoses do poder. Coimbra: Ariadne Editora, 2004. (Coleção Sofhia 002).

SOARES, Luiz Eduardo. O rigor da indisciplina. Rio de Janeiro: Relume-Dumará, 1994.

VIRILIO, Paul. A inércia polar. Lisboa: Publicações Dom Quixote, 1993.

Recebido em 15 de janeiro de 2005 e aprovado em 20 de julho de 2005 